\title{
Increased Primaquine Total Dose in Patients with Multiple Plasmodium vivax Relapses Associated with Impaired CYP2D6 Activity: Report of Three Cases
}

\section{Anielle da Pina-Costa}

FIOCRUZ: Fundacao Oswaldo Cruz

Ana Carolina Rios Silvino

FIOCRUZ CPqRR: Fundacao Oswaldo Cruz Instituto Rene Rachou

Edwiges Motta dos Santos

FIOCRUZ: Fundacao Oswaldo Cruz

Renata Pedro

FIOCRUZ: Fundacao Oswaldo Cruz

Jose Moreira

FIOCRUZ: Fundacao Oswaldo Cruz

Gabriela Robleda

FIOCRUZ: Fundacao Oswaldo Cruz

Ana Danielle Tavares

FIOCRUZ: Fundacao Oswaldo Cruz

Otilia Lupi

FIOCRUZ: Fundacao Oswaldo Cruz

Karina Henriques

FIOCRUZ: Fundacao Oswaldo Cruz

Claudio Tadeu Daniel-Ribeiro

IOC: Instituto Oswaldo Cruz

\section{Patricia Brasil}

FIOCRUZ: Fundacao Oswaldo Cruz

\section{Tais Sousa}

FIOCRUZ CPqRR: Fundacao Oswaldo Cruz Instituto Rene Rachou

Andre M Siqueira ( $\nabla$ andre.siqueira@ini.fiocruz.br)

FIOCRUZ: Fundacao Oswaldo Cruz https://orcid.org/0000-0003-2208-0294

\section{Case report}


Keywords: Plasmodium vivax, relapses, CYP2D6, primaquine, radical cure

Posted Date: February 24th, 2021

DOI: https://doi.org/10.21203/rs.3.rs-232561/v1

License: (c) (1) This work is licensed under a Creative Commons Attribution 4.0 International License. Read Full License

Version of Record: A version of this preprint was published at Malaria Journal on August 14th, 2021. See the published version at https://doi.org/10.1186/s12936-021-03869-x. 


\section{Abstract}

\section{Background}

The relapsing nature of Plasmodium vivax infection is a major barrier to its control and elimination. Factors such as adequate dosing, adherence, drug quality, and pharmacogenetics can impact the effectiveness of radical cure of $P$. vivax and need to be properly evaluated. CYP2D6 pathway mediates the activation of primaquine (PQ) into an active metabolite(s) in hepatocytes, and impaired activity has been linked to higher risk of relapse.

\section{Cases presentation}

Three patients diagnosed with $P$. vivax malaria presented repeated relapses after being initially treated with chloroquine $(25 \mathrm{mg} / \mathrm{kg})$ and primaquine $(3.5 \mathrm{mg} / \mathrm{kg}$ in 14 days $)$ at a non-endemic travel clinic. Recurring episodes were subsequently treated with higher dose of primaquine ( $7 \mathrm{mg} / \mathrm{kg}$ in 14 days), which prevented further relapses in two patients. However, one patient still presented 2 episodes after higher primaquine dose and was prescribed $300 \mathrm{mg}$ of chloroquine weekly to prevent further episodes. Impaired CYP2D6 function was observed in all of them.

\section{Conclusion}

Lack of response to PQ was associated with impaired CYP2D6 activity in three patients presenting multiple relapses followed in a non-endemic setting. Higher PQ dosage was a safe and effectively prevented relapses in two patients and should be further investigated as an option in Latin America. It is important to investigate the factors associated with unsuccessful radical cure and alternative therapeutic options.

\section{Background}

Plasmodium vivax is the most geographically widespread species causing human malaria, with approximately $40 \%$ of the world's population at risk of infection ${ }^{1-3}$. There was near 157,000 new cases in Brazil in 2019, most due P. vivax (89.1\%), of which around $21 \%$ being classified as recurrences within 60 days ${ }^{4}$. Relapses, that accounted for around 33.000 episodes that year, and earlier gametocyte production make this species especially challenging for treatment and control, but the mechanisms leading to activating hypnozoites remain unknown ${ }^{5}$.

Radical cure of vivax malaria requires antimalarial drugs that target both blood and liver stages. Primaquine $(P Q)$ is the most available drug to eliminate hypnozoites ${ }^{6,7}$. $P Q$ 's clinical effectiveness is limited by the toxicity and potential hemolytic adverse events in patients with glucose- 6 phosphate deficiency (G6PD) that is why, the drug is contraindicated during pregnancy and for infants less than six months. 
There is no definitive method to differentiate recurrences of $P$. vivax as recrudescence, especially with increasing evidence of resistance to chloroquine $(\mathrm{CQ})^{8}$, relapses, and reinfection in areas with active transmission. The possibility of following patients in non-endemic areas provides an advantage where at least reinfection could be excluded. Recent studies in Brazil showed that recurrences rates in the Amazon setting range from $29.4 \%$ to $39.6 \%$ in Amazon and non-Amazon areas ${ }^{9-11}$, despite PQ's routine prescription. It was recently described that cytochrome P450 2D6 (CYP2D6) pathway mediates the activation of primaquine into active phenolic metabolite(s) in hepatocytes ${ }^{12,13}$ and some genetic polymorphisms implied in reduced $P Q$ metabolism have been associated with higher risk of relapse ${ }^{14}$. Individuals with specific CYP2D6 polymorphic alleles fail to metabolize PQ and may experience treatment failure, leading to false assumptions of PQ efficacy and tolerance.

CYP2D6 gene is highly polymorphic with over 150 alleles categorized in no, decreased, normal, and increased function alleles based on enzyme activity ${ }^{15}$. The CYP2D6 allele combinations give rise to different predicted metabolizer phenotypes: poor (gPM), intermediate (gIM), normal (gNM), and ultrarapid (gUM) metabolizers ${ }^{15}$. Therefore, vivax malaria patients with the defective CYP2D6 function would be at increased risk for therapeutic failure (relapses) regardless of proper treatment regimens with $\mathrm{PQ}^{14,16-18}$. Thereat, to identify patients at a higher risk for recurrences CYP2D6 metabolizer status provides valuable information in improving the interpretation of treatment failure in $P$. vivax and strengthening the efforts to control this parasite. Herein, we describe three cases of multiple vivax malaria relapses in individuals with impaired CYP2D6 metabolic activity followed-up at a non-endemic area in Brazil. The individual responses to different drug schemes varied related to CYP2D6 metabolic status and showed to be complex.

\section{Site and standard procedures:}

The Instituto Nacional de Infectologia Evandro Chagas (INI) is a reference center for diagnosing and treating infectious diseases at Fundação Oswaldo Cruz (Fiocruz), in Rio de Janeiro, Brazil. Patients with suspicion of malaria are evaluated by infectious disease physicians and follow the national malaria treatment guidelines. The guidelines state that vivax malaria should be treated with CQ $(25 \mathrm{mg} / \mathrm{kg}$ during three days) and $\mathrm{PQ}(3.5 \mathrm{mg} / \mathrm{kg}$ during seven or 14 days). Blood slides were collected by experienced microscopists and malaria species confirmed by polymerase chain reaction (PCR) ${ }^{19,20}$. Patients were followed until parasitological clearance and routinely at days $3,7,14,21,28,40$, and 60 post-treatment and at any time in case of recurring fever. All patients were tested for G6PDd. PQ was adjusted for body weight (bw) when necessary. None of the patients returned to the endemic area.

\section{CYP2D6 genotyping}

Genotyping of one tri-nucleotide deletion (2615-2617delAAG [rs5030656]), eight single-nucleotide polymorphisms (SNPs) (-1584C>G [rs1080985], 100C >T [rs1065852], 1023C>T [rs28371706], 1846G>A [rs3892097], 2850C >T [rs16947], 2988G >A [rs28371725], 3183G >A [rs59421388], 4180G>C [rs1135840]) and CYP2D6 copy number analysis were performed by Real-Time PCR, according to protocols previously 
described $^{16,22}$. CYP2D6 haplotypes were inferred from genotypes using the software PHASE v.2.123,24 and phenotypes were predicted based on activity score (AS) model ${ }^{15}$. Patients were categorized into five predicted phenotype classes: poor metabolizer ( $(\mathrm{gPM}$; AS score $=0)$, intermediate metabolizer ( $\mathrm{gIM}$; AS score $=0.5$ ), normal-slow metabolizer (gNM-S; AS score $=1$ ), normal-fast metabolizer (gNM-F; AS score 1.5-2.0), and ultrarapid metabolizer (gUM ; AS score > 2).

Ethical approval was obtained from the INI-Fiocruz Ethical Board (number 0020.0.009.000-07), and all participants provided informed written consent.

\section{Case Presentation}

Herewith we describe three cases of $P$. vivax malaria infection which presented multiple recurrences. All patients remained in the non-transmission area throughout the follow-up. Due to the lack of tools for differentiating relapses from recrudescence, we applied the proposed criteria of classifying recurrences as recrudescence if happening with less than 28 days post-treatment and as relapses if occurring after this period. There was no risk of reinfection for the cases.

Case 1: Male, 32 years-old (yo), 78.5 kg of body weight (bw), resided in São Gabriel da Cachoeira (Amazon state - AM) for two years (until 18 Dec 2015) where he had a diagnosis of vivax malaria on $1^{\text {st }}$ Nov 2015 being treated with chloroquine (CQ) and primaquine (PQ) for seven days (Figure 1). On 25 Jan 2016, 38 days after having moved to Rio de Janeiro city (and 85 days after the initial diagnosis), he sought care at INI and was diagnosed with $P$. vivax infection (18.320 parasites $\left./ \mathrm{mm}^{3}\right)$. G6PD activity was tested normal. He was treated with $\mathrm{CQ}$ and $\mathrm{PQ}$ (total dose of $\mathrm{PQ}: 3.44 \mathrm{mg}$ base/ $\mathrm{kg}$ given during nine days). On 16 Apr 2016 (81-days interval), he presented another malaria episode diagnosed as $P$. vivax (6.000 parasites $/ \mathrm{mm}^{3}$ ). He was then treated with $\mathrm{CQ}$ and higher-dose $\mathrm{PQ}$ (total dose of PQ: $7.03 \mathrm{mg}$ base/kg bw given in 22 days). CYP2D6 genotype was performed and classified as intermediate metabolizer (Table 1). He was followed-up for more than one year and has not presented new episodes until 20 Jun 2017.

Case 2: Female, 33 yo, 62.3 kg of bw, resided in São Gabriel da Cachoeira/AM until 14 Nov 2015 where she was diagnosed and treated for vivax malaria on $1^{\text {st }}$ Oct 2015 (Figure 1). In Rio de Janeiro, she was diagnosed with P. vivax on 18 Feb 2016 (12.480 parasites $/ \mathrm{mm}^{3}$ ) and was treated with CQ and PQ (total dose of PQ: $3.37 \mathrm{mg}$ base/ kg bw given in seven days). G6PD activity was normal. On 5 Apr 2016, she presented to INI with a vivax relapse (46-days interval). She received CQ and PQ (total dose of PQ: 7.02 $\mathrm{mg}$ base/ kg bw given in seven days) and she remained without further episodes (updated 20 Jun 2017). Her CYP2D 6 was classified as poor metabolizer (Table 1).

Case 3: Male, 56 yo, $82 \mathrm{~kg}$ of bw, resided in Machadinho do Oeste/Rondônia State (Amazon region) for two months until 4 Aug 2016 where he received treatment for vivax malaria on $1^{\text {st }}$ Jul 2016 (Figure 1). After returning to Rio de Janeiro, he presented four episodes of malaria, with roughly similar intervals. For these episodes, the respective treatments were administered: CQ + PQ (total dose: $3.21 \mathrm{mg} / \mathrm{kg}$ ); CQ + PQ 
(total dose: $3.21 \mathrm{mg} / \mathrm{kg}$ ); $\mathrm{CQ}+\mathrm{PQ}$ (total dose: $7 \mathrm{mg} / \mathrm{kg}$ ); Artemether-Lumefantrine (AL) + PQ (total dose: 7 $\mathrm{mg} / \mathrm{kg}$ ) - AL was administered due to CQ-induced pruritus. CYP2D6 genotype was classified as normalslow metabolizer (Table 1). On 8 May 2017, after discussion with the patient a decision to perform CQ prophylaxis (300mg per week for eight weeks) was taken. The patient is still under follow-up (update 20 Jun 2018) and has not had new episodes.

\section{Discussion And Conclusions}

We report three individuals who presented a varied number of $P$. vivax relapses for which an impaired CYP2D6 activity was observed, suggesting that those abnormalities are implicated in the risk of $P$. vivax malaria recurrence after treatment with chloroquine/primaquine. Our data corroborate with a developing body of knowledge that supports host genetics as a cause for $P Q$ drug failure in individuals who experience $P$. vivax relapse. Whether routine screening of CYP2D6 alleles in patients who experience $P$. vivax malaria relapse in endemic settings is feasible and cost-effective is a matter that should be investigated. Next, more robust evidence is needed to identify the alternative treatment regimens in CYP2D6 impaired patients. To address those issues, we are planning the largest, multicenter Brazilian cohort study to elucidate the relationship between CYP2D6 activity, geographic regional dosing requirements, and clinical failure of primaquine for radical cure of vivax malaria.

$P$. vivax is the most geographically widespread species causing human malaria. its resilience to control and elimination efforts mainly result from its complex biology. The origin of a recurring parasitemia following a primary infection by $P$. vivax can be a result of (i) recrudescence due to resistance to the blood schizonticidal drug - usually chloroquine; (ii) relapse from activated hypnozoites - which is a particularity of $P$. vivax and $P$. ovale amongst human malaria; or (iii) reinfection in areas where active transmission exist ${ }^{7}$. Relapses can be responsible for up to $80 \%$ of the malaria burden in given settings ${ }^{25}$, with evidence suggesting that its relative contribution increases in declining transmission intensity ${ }^{9}$. The factors that trigger the hypnozoite activation are not completely understood and, strain-specific patterns, environmental factors, and host characteristics have been implicated as potential contributors. For the last six decades, $\mathrm{PQ}$, an 8-aminoquinoline derivative, has been the only drug with anti-relapse activity available. Its use was restricted due to the hemolytic potential in individuals with G6PD ${ }^{27}$. Although the exact mechanism throughout $P Q$ exerts its anti-relapse activity is not known, the recent finding the slow metabolizers have higher rates of relapses has added stronger evidence that a still unknown metabolite is responsible for its effect ${ }^{14,16}$.

There are no molecular methods to reliably distinguish amongst the causes of recurrence for $P$. vivax as there are for $P$. falciparum. Standardized molecular methods allow differentiation between recrudescence and reinfection ${ }^{28}$. In our study relapses occurred in a non-endemic area and all subjects did not travel to any $P$. vivax endemic region after the initial episodes, thereby reducing the possibility that confounding variables were responsible for the observed relapse infection. Recrudescence due to erythrocytic parasites was not probable since the parasitemia decreased in the blood and therapeutic failure in the presence of 
drug was not reported. The minimum interval between episodes was 52 days (median $=91$, maximum $=$ 136), which supports the classification of these recurrences as relapses, since recrudescence due to erythrocytic stage parasites usually occur within 28 days after treatment with $\mathrm{CQ}^{27}$.

Patients were oriented about the importance of treatment and of reporting adverse events during the follow-up period as well as returning to the clinic in case of symptoms. None of them returned to an endemic area and presented new symptoms after the malaria therapeutic period. The three subjects were tested negative for G6PDd, and the woman was not pregnant or breastfeeding. Consequently, the patients were eligible to receive primaquine, discarding contraindication to $P Q$ use. The results reported here corroborate partially with Deepika et al. study ${ }^{29}$, indicating the use of higher total doses of primaquine to prevent relapses. Drugs weight-adjusted during the treatment are essential and all patients were treated with high dose of primaquine. Two of them did not present relapses anymore. However, for one of the cases (case \#3) a decision to institute weekly chloroquine prophylaxis was taken because relapses occurred even with primaquine in high doses. Of importance, none of the subjects had comorbidities or were using any non-antimalarial medication. Therefore, it is unlikely that host factors such as drug-drug and drug-CYP2D6 interactions influenced the pharmacokinetics and metabolism of PQ by CYP2D6.

Our study has limitations. First, individual CYP2D6 phenotype was inferred from genotyping data, according to activity scores of CYP2D6 diplotypes and there is evidence for considerable range of variation in CYP2D6 function within genotype-inferred phenotype categories. Second, although true primaquine resistance could not be rule out, but considering the early parasitological cure observed after the combined CQ/PQ treatment, the most likely explanation is that the cause of the successive recurrences was due to $P Q$ failure and not $P Q$ resistance. Third, $P Q$ administration was not supervised and the possibility of non-adherence may not be excluded. Nevertheless, all the patients reinforced that the full dosage of PQ has been completed in all episodes, and all attended the follow-up appointments.

This case-series, along with previous studies, points out that CYP2D6 as a possible important determinant of efficacy of primaquine against relapse. A relevant issue for clinical management and consequently control and elimination is how to achieve better radical cure and to classify and treat recurring episodes. Considering the burden of relapses and its public health implications for the elimination of vivax malaria in Latin America, we are conducting a 1-year cohort, multicenter, therapeutic efficacy study of $C Q$ and $P Q$ in distinct malaria transmission intensity locations in Brazil to estimate the frequency, timing, and associated risk factors for the developing of recurrences (ABRACAMAL project, Gates foundation grant INV-003970). Thus, we aim, to provide a comprehensive framework for estimate the radical curative failure rate and thereby contribute to an improved understanding of the biology, epidemiology, and treatment of $P$. vivax malaria that may lead to more effective management policies.

\section{Abbreviations}

$\mathrm{AL}$ - artemether-lumefantrine 
AS - activity score

bw - body weight

$\mathrm{CQ}$ - chloroquine

CYP2D6- cytochrome P450 2D6

Fiocruz - Fundação Oswaldo Cruz

G6PDd - glucose-6 phosphate deficiency

gIM - intermediate metabolizer

gNM - normal metabolizer

gPM - poor metabolizer

gUM - ultrarapid metabolizer

INI - Instituto Nacional de Infectologia Evandro Chagas

PCR - polymerase chain reaction

$\mathrm{PQ}$ - primaquine

SNPs - single-nucleotide polymorphisms

yo - years-old

\section{Declarations}

\section{COMPETING INTERESTS}

The authors declare that they have no competing interests related to this study.

\section{AUTHORS' CONTRIBUTIONS}

The authors confirm contribution to the paper as follows: study conception and design: APC, CTDR, PB, TNS and AMS; data collection: APC, ACRS, EMS, RSP, JM, GLU, ADTS, OHLRS, KMDH and AMS; analysis and interpretation of results: APC, ACRS, EMS, CTDR, ; draft manuscript preparation: APC, RSP, JM, CTDR, $\mathrm{PB}, \mathrm{TNS}$ and AMS. All authors reviewed the results and approved the final version of the manuscript.

\section{ACKNOWLEDGEMENTS}

We acknowledge the support of Bill \& Melinda Gates Foundation and the Brazilian Ministry of Health in funding this study (INV-003970). This work was supported by Fundação de Amparo à Pesquisa do 
Estado de Minas Gerais (FAPEMIG; APQ-00952-16). The authors thank the Program for Technological Development in Tools for Health-PDTIS-Fiocruz for use of the Real-Time PCR (RPT09D) facility. ACRS thanks the Coordenação de Aperfeiçoamento de Pessoal de Nível Superior - Brasil (CAPES) - for scholarship support (Finance Code 001). CTDR is recipient of a Cientista do Nosso Estado and AMS recipient of a Jovem Cientista do Nosso Estado fellowships from FAPERJ and CTDR and TNS are recipients of CNPq Research Productivity Fellowship. The Laboratório de Pesquisa em Malária (LPM, IOC, Fiocruz) is a National Institute of Science \& Technology (INCT) Associated Laboratory and an Associated Laboratory of the Neuroinflammation Network (Faperj).

\section{References}

1. Price RN, Tjitra E, Guerra CA, Yeung S, White NJ, Anstey NM. Vivax malaria. Am J Trop Med Hyg. 2007 Dec;77(6 Suppl):79-87.

2. Gething PW, Elyazar IRF, Moyes CL, Smith DL, Battle KE, Guerra CA, et al. A Long Neglected World Malaria Map: Plasmodium vivax Endemicity in 2010. PLoS Negl Trop Dis [Internet]. 2012 Sep 6 [cited 2018 Oct 8];6(9). Available from: https://www.ncbi.nlm.nih.gov/pmc/articles/PMC3435256/

3. Howes RE, Battle KE, Mendis KN, Smith DL, Cibulskis RE, Baird JK, et al. Global Epidemiology of Plasmodium vivax. Am J Trop Med Hyg. 2016 Dec 28;95(6 Suppl):15-34.

4. Brazilian Ministry of Health. Sistema de informação de agravos de notificação - Sinan Net 2009. [Internet]. 2017 [cited 2017 Oct 13]. Available from: http://portalsinan.saude.gov.br/

5. Hulden L, Hulden L. Activation of the hypnozoite: a part of Plasmodium vivax life cycle and survival. Malar J. 2011;10(1):90.

6. Galappaththy GN, Tharyan P, Kirubakaran R. Primaquine for preventing relapse in people with Plasmodium vivax malaria treated with chloroquine. Cochrane Database Syst Rev [Internet]. 2013 [cited 2018 Oct 8]; Available from: https://www.readcube.com/articles/10.1002/14651858.CD004389.pub3

7. Maneerattanasak S, Gosi P, Krudsood S, Chimma P, Tongshoob J, Mahakunkijcharoen Y, et al. Molecular and immunological analyses of confirmed Plasmodium vivax relapse episodes. Malar $\mathrm{J}$ [Internet]. 2017 Dec [cited 2018 Apr 9];16(1). Available from: http://malariajournal.biomedcentral.com/articles/10.1186/s12936-017-1877-x

8. Commons RJ, Simpson JA, Thriemer K, Humphreys GS, Abreha T, Alemu SG, et al. The effect of chloroquine dose and primaquine on Plasmodium vivax recurrence: a WorldWide Antimalarial Resistance Network systematic review and individual patient pooled meta-analysis. Lancet Infect Dis [Internet]. $2018 \mathrm{Jul}$ [cited 2018 Aug 7]; Available from: https://linkinghub.elsevier.com/retrieve/pii/S1473309918303487

9. Vitor-Silva S, Siqueira AM, de Souza Sampaio V, Guinovart C, Reyes-Lecca RC, de Melo GC, et al. Declining malaria transmission in rural Amazon: changing epidemiology and challenges to achieve elimination. Malar J [Internet]. 2016 Dec [cited 2018 Oct 8];15(1). Available from: http://malariajournal.biomedcentral.com/articles/10.1186/s12936-016-1326-2 
10. Pedro RS, Guaraldo L, Campos DP, Costa AP, Daniel-Ribeiro CT, Brasil P. Plasmodium vivax malaria relapses at a travel medicine centre in Rio de Janeiro, a non-endemic area in Brazil. Malar J. 2012;11(1):245.

11. Katsuragawa TH, Gil LHS, Tada MS, Costa JDN. The Dynamics of Transmission and Spatial Distribution of Malaria in Riverside Areas of Porto Velho, Rondo^ nia, in the Amazon Region of Brazil. PLoS ONE. 2010;5(2):12.

12. Potter BMJ, Xie LH, Vuong C, Zhang J, Zhang P, Duan D, et al. Differential CYP 2D6 Metabolism Alters Primaquine Pharmacokinetics. Antimicrob Agents Chemother. 2015 Apr;59(4):2380-7.

13. Pybus BS, Sousa JC, Jin X, Ferguson JA, Christian RE, Barnhart R, et al. CYP450 phenotyping and accurate mass identification of metabolites of the 8-aminoquinoline, anti-malarial drug primaquine. Malar J. 2012;11(1):259.

14. Bennett JW, Pybus BS, Yadava A, Tosh D, Sousa JC, McCarthy WF, et al. Primaquine Failure and Cytochrome P-450 2D6 in Plasmodium vivax Malaria. N Engl J Med. 2013 Oct 3;369(14):1381-2.

15. Gaedigk A, Ingelman-Sundberg M, Miller NA, Leeder JS, Whirl-Carrillo M, Klein TE. The Pharmacogene Variation (PharmVar) Consortium: Incorporation of the Human Cytochrome P450 (CYP) Allele Nomenclature Database. Clin Pharmacol Ther. 2018 Mar;103(3):399-401.

16. Silvino ACR, Costa GL, Araújo FCF de, Ascher DB, Pires DEV, Fontes CJF, et al. Variation in Human Cytochrome P-450 Drug-Metabolism Genes: A Gateway to the Understanding of Plasmodium vivax Relapses. Renia L, editor. PLOS ONE. 2016 Jul 28;11(7):e0160172.

17. Brasil LW, Rodrigues-Soares F, Santoro AB, Almeida ACG, Kühn A, Ramasawmy R, et al. CYP2D6 activity and the risk of recurrence of Plasmodium vivax malaria in the Brazilian Amazon: a prospective cohort study. Malar J [Internet]. 2018 Dec [cited 2018 Apr 9];17(1). Available from: https://malariajournal.biomedcentral.com/articles/10.1186/s12936-017-2139-7

18. Ingram RJH, Crenna-Darusallam C, Soebianto S, Noviyanti R, Baird J. The clinical and public health problem of relapse despite primaquine therapy: case review of repeated relapses of Plasmodium vivax acquired in Papua New Guinea. Malar J. 2014;13(1):488.

19. Brazilian Ministry of Health. Manual of Malaria Laboratory Diagnosis [Internet]. 2005 [cited 2018 Aug 7]. Available from: http://bvsms.saude.gov.br/bvs/publicacoes/malaria_diag_manual_final.pdf

20. Torres KL, Figueiredo DV, Zalis MG, Daniel-Ribeiro CT, Alecrim W, Ferreira-da-Cruz M de F. Standardization of a very specific and sensitive single PCR for detection of Plasmodium vivax in low parasitized individuals and its usefulness for screening blood donors. Parasitol Res. 2006 May;98(6):519-24.

21. Brazilian Ministry of Health. Malaria's treatment in Brazil practical guide [Internet]. 2010 [cited 2018 Aug 7]. Available from: http://bvsms.saude.gov.br/bvs/publicacoes/guia_pratico_malaria.pdf

22. Friedrich DC, Genro JP, Sortica VA, Suarez-Kurtz G, de Moraes ME, Pena SDJ, et al. Distribution of CYP2D6 Alleles and Phenotypes in the Brazilian Population. Carvalho LH, editor. PLoS ONE. 2014 Oct 20;9(10):e110691. 
23. Stephens M, Smith NJ, Donnelly P. A New Statistical Method for Haplotype Reconstruction from Population Data. Am J Hum Genet. 2001 Apr;68(4):978-89.

24. Stephens M, Donnelly P. A Comparison of Bayesian Methods for Haplotype Reconstruction from Population Genotype Data. Am J Hum Genet. 2003 Nov;73(5):1162-9.

25. Betuela I, Rosanas-Urgell A, Kiniboro B, Stanisic DI, Samol L, de Lazzari E, et al. Relapses Contribute Significantly to the Risk of Plasmodium vivax Infection and Disease in Papua New Guinean Children 1-5 Years of Age. J Infect Dis. 2012 Dec 1;206(11):1771-80.

26. Battle KE, Karhunen MS, Bhatt S, Gething PW, Howes RE, Golding N, et al. Geographical variation in Plasmodium vivax relapse. Malar J. 2014;13(1):144.

27. Baird JK. Resistance to Therapies for Infection by Plasmodium vivax. Clin Microbiol Rev. 2009 Jul;22(3):508-34.

28. World Health Organization. Methods and techniques for clinical trials on antimalarial drug efficacy: genotyping to identify parasite populations: informal consultation organized by the Medicines for Malaria Venture and cosponsored by the World Health Organization, 29-31 May 2007, Amsterdam, The Netherlands. Genève: World Health Organization; 2008.

29. Fernando D, Rodrigo C, Rajapakse S. Primaquine in vivax malaria: an update and review on management issues. Malar J. 2011 Dec 12;10:351.

30. Gaedigk A, Dinh J, Jeong H, Prasad B, Leeder J. Ten Years' Experience with the CYP2D6 Activity Score: A Perspective on Future Investigations to Improve Clinical Predictions for Precision Therapeutics. J Pers Med. 2018 Apr 17;8(2):15.

31. Baird JK, Battle KE, Howes RE. Primaquine ineligibility in anti-relapse therapy of Plasmodium vivax malaria: the problem of G6PD deficiency and cytochrome P-450 2D6 polymorphisms. Malar J [Internet]. 2018 Jan 22 [cited 2018 Apr 24];17. Available from:

https://www.ncbi.nlm.nih.gov/pmc/articles/PMC5778616/

32. St Jean PL, Xue Z, Carter N, Koh GCKW, Duparc S, Taylor M, et al. Tafenoquine treatment of Plasmodium vivax malaria: suggestive evidence that CYP2D6 reduced metabolism is not associated with relapse in the Phase 2b DETECTIVE trial. Malar J [Internet]. 2016 Dec [cited 2018 Oct 8];15(1). Available from: http://www.malariajournal.com/content/15/1/97

\section{Tables}

Table 1 not available with this version

\section{Figures}



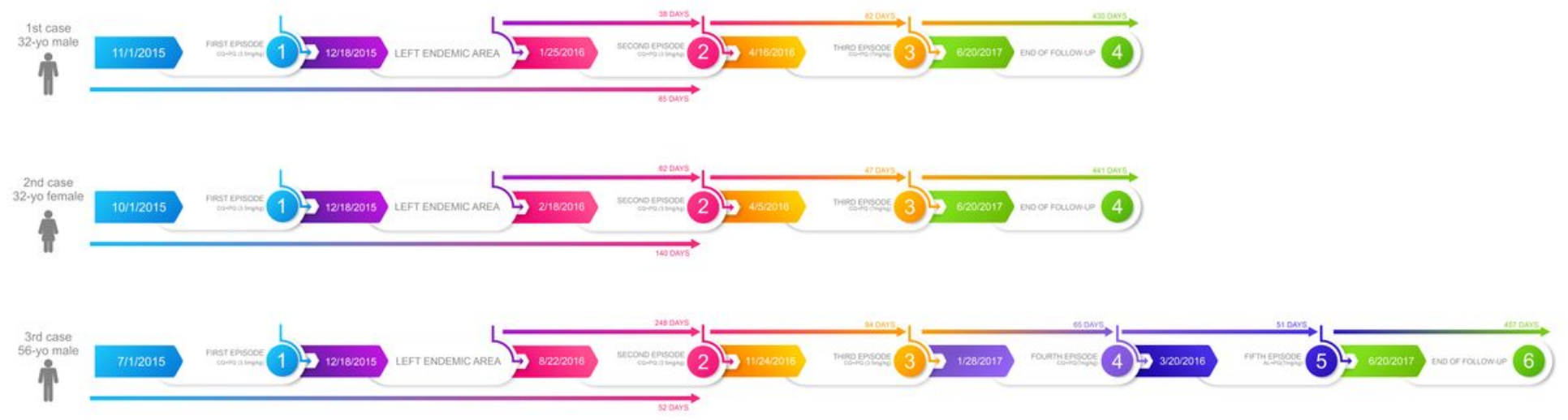

Figure 1

Dates and treatment regimens prescribed for the three cases. 